Journal of Sustainable Development of Transport and Logistics journal home page: https://jsdtl.sciview.net

Suo, Q., Suo, R., \& Zhang, D. (2018). Investigation and statistical analysis on the deterrence effect of police patrol. Journal of Sustainable Development of Transport and Logistics, 3(3), 69-76. doi:10.14254/jsdtl.2018.3-3.5.

\title{
Investigation and statistical analysis on the deterrence effect of police patrol
}

\author{
Qinghui Suo ${ }^{1}$, Ruijun Suo ${ }^{2}$, Daming Zhang ${ }^{1}$ \\ ${ }^{1}$ School of Engineering and Technology, Southwest University, \\ No.2 Tiansheng Road Beibei District,Chongqing 400715, P. R. China \\ ${ }^{2}$ School of Urban Construction, Yangtze University, \\ 1 Nanhuan Road Jingzhou Hubei, P. R. China
}

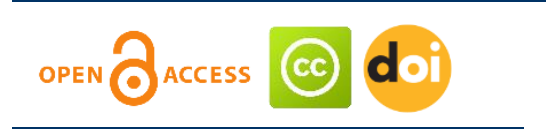

\section{Article history:}

Received: December 23,

2017

1st Revision: March 15, 2018

Accepted: November 29,

2018

\section{DOI:}

10.14254/jsdtl.2018.3-3.5

\begin{abstract}
This study investigated the deterrence effect of the police patrol on the road safety in China and the research purpose was achieved by questionnaire survey and data regression. Firstly, a questionnaire survey was carried out to investigate the drivers' illegal behaviours and attitudes to safety measures, such as police patrol, surveillance cameras and warning signs, and 137 drivers participated in the survey; the statistical results showed that $45.3 \%, 4.4 \%$ and $16.8 \%$ of the respondents had the experience of speeding, driving under influencing of alcohol and fatigued driving respectively; all of the participants believed that traffic police patrol would change their dangerous driving behaviours and police patrol is most effective among three road safety measures based on the investigations. Secondly, data about police patrol frequency and road crash rate on the road segment was collected from the local Transportation Administration Bureau and the regression analysis based on the data was conducted to investigate the direct effect of traffic police patrol on road safety improvement. The results indicated that increasing the frequency of police patrol has an obvious positive effect on improving the road safety and it is consistent with the results from self-reported questionnaire survey.
\end{abstract}

Keywords: road crash, safety measure, drivers' behaviour and attitude, deterrence effects.

\section{Introduction}

China has been experiencing motorization process due to a rapid economic growth (Suo, Zhang \& Liu, 2017). As a result, road safety has become a major problem for public health. For instance, throughout the year of 2012, 210,812 road crashes were recorded in China's road system and 62,387 peoples were killed according to the official statistics (National Bureau of Statistics of the PRC, 2013). Zhang's analysis showed that drivers' errors, such as driving-and-drinking, speeding and fatigue-

Corresponding author: Qinghui Suo

E-mail: suo@swu.edu.cn

This open access article is distributed under a Creative Commons Attribution (CC-BY) 4.0 license. 
driving, are some of the main causes associated with road crashes in China (Zhang, Tsimhoni, Sivak \& Flannagan, 2010).

China has put considerable efforts towards engineering, education and enforcement to reduce the road crashes (Liu, Ding \& Wang, 2015); however, there is a large potential for China under more intensive road supervision to improve the safety of its road system. One of the efforts is to establish rigorous law and intensify law enforcement. Law of the People's Republic of China on Road Traffic Safety came into force on May 12004 and it is the fist-ever law on road traffic safety in china. This Law is enacted with a view to maintaining road traffic order, taking precautions against and reducing traffic accidents, protecting personal safety, safeguarding the safety of property and other lawful rights and interests of citizens, legal persons and other organizations, and increasing passage efficiency (National People's Congress of PRC, 2004). By 2015 the law has been updated for several times and punishment measures on most of illegal driving behaviours have become more and more severe; for example, criminal responsibilities shall be applied to behaviour of drunk driving since May 12011 (National People's Congress of PRC, 2011).

Deterrence is the use of punishment as a threat to deter people from offending. The concept of deterrence has two key assumptions: the first is that specific punishments imposed on offenders will deter or prevent them from committing further crimes; the second is that fear of punishment will prevent others from committing similar crimes (Wright, 2010). Deterrence theory is the dominant ideology in law enforcement to reduce illegal driving behaviours (Lapham \& Todd, 2012) which hypothesizes that law breaking is inversely proportional to the swiftness, certainty and severity of punishment (Taxman \& Piquero, 1998) and works through the certainty, celerity (or swiftness) and severity of punishment for a given behaviour (Grosvenor, Toomy \& Wagenaar, 1999). Law enforcement aims to prevent traffic offences by increasing the objective and subjective chance of getting caught, when drivers see this chance as being sufficiently high, they will avoid traffic offences (European Commission, 2007); it should be able to create a deterrent effect to the drivers and ensure that perceived apprehension risk is high. Traffic police officers play a very important role in reducing road crash and improving traffic safety by conducting sufficient police patrols (Yannis, Papadimitriou \& Antoniou, 2007; Kuo, Lord \& Walden, 2013). Numerous attempts have been made to increase the effectiveness of police enforcement in reducing traffic crashes and most attempts have involved increasing police presence. Many scholars have investigated the relationship between the traffic police presence and the road crash rate (Vaa, 1997; Newstead, Cameron \& Leggett, 2001; Hakkert, Gitelman, Cohen, Doveh \& Umansky, 2001; Briscoe, 2004; Yannis, Papadimitriou \& Antoniou, 2008; Elvik, 2011; Stanojević, Jovanović \& Lajunen, 2013; Chang, Lin, Huang \& Chang, 2013).

In this paper, the effects of safety measures, especially traffic police patrol, on the road safety improvement in China were investigated. Firstly, a questionnaire survey was carried out to investigate drivers' behaviours and attitudes to police patrol, surveillance cameras and road warning signs on a road segment; then data about police patrol frequency and road crash rate on the road segment was collected from the local Transportation Administration Bureau, and finally regression analysis was conducted to investigate the direct effect of traffic police patrol on road safety improvement.

\section{Methods for data collection}

As the lack of a comprehensive and reliable road safety database nationally, the data adopted in this study was collected on a road segment of $58.4 \mathrm{~km}$ in length linking two small towns. Traffic police patrol, road surveillance cameras and traffic warning signs are the main safety measures applied on the road segment by local road administration department while investigation. The drivers' attitudes to the safety measures were studied by self-reported questionnaire and the data about traffic police patrol and road crash from January 12010 to May 42012 ( $\mathrm{T}=854$ days) on the road were provided by local Transportation Administration Bureau. During the investigation period there were 46 crashes on the road. It was identified that driving under the influence of alcohol (DUIA), speeding, fatigued driving and pedestrians' jaywalking are the primary reasons for the crashes on the road segment; the proportional composition of road crashes is shown in Fig. 1. According to the Road Traffic Safety Law of the People's Republic of China, DUIA is divided into two categories: driving after drinking is the condition that driver's blood alcohol content (BAC) between $20 \mathrm{mg} / 100 \mathrm{ml}$ and $80 \mathrm{mg} / 100 \mathrm{ml}$ and if driver's BAC equal to or above a threshold level of $80 \mathrm{mg} / 100 \mathrm{ml}$ is drunk driving; fatigued driving is defined as driving 
continually for 4 hours without a break according to the law which would slow driver's reaction time, decrease awareness and impair judgment; the maximum speed limit on the road investigated is 80 $\mathrm{km} / \mathrm{h}$. the severity of punishment on speeding is divided into five degrees depending on the degrees of speed.

\section{Figure 1: Proportional composition of road crashes}

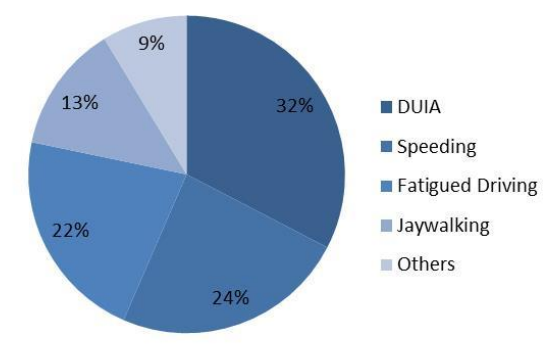

During the period, the followings conditions have been changed: the Road Traffic Safety Law of the People's Republic of China was revised on May 12011 for the third time, for example law items about penalties for driving after drinking have been updated; the road segment has gone through a small scale repair from August 2010 to September 2010 except the routine maintenances. The frequency of traffic police patrol (patrol / day) and the frequency of road crash (crash / day) vary from day to day. The following conditions were stressed when counting the police patrol frequency:

1. According to the administration regulations of the local TAB, the traffic polices conduct the road patrolling for at least 5 times per day up to 15 times per day,

2. The program of traffic police patrol is the combination of stationary overseeing at fixed point and random scheduled mobile patrol on the road,

3. In the special days, such as spring festival and national day, more patrol vehicles were allocated to the road and

4. While the traffic police officers were visible to the drivers, such as being handling road crash on the road, it was counted as one patrol.

\section{Questionnaire survey}

Firstly, a questionnaire survey was carried out to investigate the licensed drivers' behaviours and attitudes to the safety measures; the participants for the survey were randomly chosen at the gas station located beside the road. The investigators spent 5-10 minutes to made a brief introduction of the survey purpose to the driver and then the driver was invited to help finish the survey forms, after that 20RMB (about 3 US\$) was paid to each respondent as a reimbursement. 200 drivers were contacted and 137 drivers (129 males and 8 females) finished questionnaires with a response rate of $68.5 \%$. As most of the crashes on the road during the investigation period were caused by drivers' misconducts according to records (see Fig. 1), the first survey focus on drivers' past experience of illegal behaviour, such as speeding, DUIA and fatigued driving (see Table 1).

Table 1: Questions and results

\begin{tabular}{lccc} 
Questions & & \multicolumn{2}{c}{$\begin{array}{c}\text { Please Circle One } \\
\text { (Number \%) }\end{array}$} \\
\hline Have you ever had the experience of & speeding? & Yes(45.3\%) & No(54.7\%) \\
& DUIA? & Yes(4.4\%) & No(95.6\%) \\
& fatigued driving? & Yes(16.8\%) & No(83.2\%) \\
\hline
\end{tabular}

The percentage of respondents answered "Yes" for speeding, DUIA and fatigued driving are 45.3\%, $4.4 \%$ and $16.8 \%$ respectively. Almost half of the respondents admitted that they have the experience of speeding and it is an extremely high ratio. The drivers were also asked about the question that "Do you know the upper speed limit of this road segment?" and 6 of 137 drivers answered "No" which means that they did not pay attention to the traffic warning signs about speed limit. According to road traffic 
safety law, monetary fine is the primary punishment measure applied to deter speeding in China, only if high perception of being caught for this behaviour, the monetary fine does not seem to be effective. Speed radar was not installed on the road during the investigation period, which has been proven to be effective in most of cities and express highways. For DUIA, only $4.4 \%$ respondents declared that they have had the dangerous behaviour. The ratio of respondents participated in our investigation who reported the experience of DUIA is low but crash ratio caused by DUIA is high on the road (32\%, see Fig. 1); DUIA is a very dangerous driving behaviour and it has high potential risk to induce road crash. Alcohol is part of Chinese folklore and liquor is the main drink to show respect and happiness in Chinese culture. Li et al. indicated that at least 20 percent of serious road crashes were alcohol related based on the investigations in 2 Chinese southern cities (Li, Xie, Nie \& Zhang, 2012). Although there were no national level statistics on the driving after drinking, it was still identified that DUIA is one of the main causes associated with road crashes in China. China has been concerning about the serious problem and put considerable efforts into preventing people from driving after drinking, these efforts include establishing rigorous law and implementing random roadside breath testing. $16.8 \%$ of respondents reported fatigued driving experience. In China fatigued driving rarely happens to family car drivers; the professional drivers, such as truck drivers, taxi drivers and coach drivers, have a higher likelihood of the offense. This kind of illegal behaviour is difficult for the traffic polices to identify even after they stop the vehicles.

The drivers were also invited to finish the questionnaire 2 (Table 2). In this survey, the drivers were asked to answer the questions "Does the safety measure (traffic police patrol, road surveillance camera or traffic warning signs) correct your illegal driving behaviour?" and they respond on a threepoint Likert scale ranged from "Yes", "Not sure" to "Not". 100\%, 71.5\% and 31.4\% of the respondents answered "yes" for each safety measure. From the self-reported results, it is easy to see that all drivers participated in the survey believed that traffic police patrol would change their dangerous driving behaviour and police patrol was ranked highest as a subjective ranking by drivers; road surveillance cameras installed on the road rank the second.

\begin{tabular}{lcccc} 
Table 2: Questions and results & \multicolumn{3}{c}{ Please Circle One } \\
\multicolumn{1}{c}{ Questions } & & \multicolumn{3}{c}{ (Number of Respondents) } \\
\hline Does the safety measure correct & Traffic police patrol & Yes & Not Sure & No \\
your illegal driving behaviour? & & $(137)$ & $(0)$ & $(0)$ \\
& & Road surveillance cameras & Not Sure & No \\
& & $(98)$ & $(32)$ & $(7)$ \\
& \multirow{2}{*}{ Traffic warning signs } & Yes & Not Sure & No \\
& & $(43)$ & $(69)$ & $(25)$ \\
\hline
\end{tabular}

\section{Data process and analysis}

In this part, the mathematical relationship between the frequency of traffic police patrol (patrol/day) and the frequency of accidents (accident/day) on the road segment is built. As the traffic police patrol frequency varies from 5 patrol/day to 15 patrol/day, the investigation period $\mathrm{T}=854$ days is divided into 11 groups based on the police patrol frequency as $T_{5}, T_{6}, \cdots, T_{i}, \cdots, T_{15}$, then $\sum_{i=5}^{15} T_{i}=854$ days. $T_{5}=15$ represents the cumulated days while patrol frequency is 5 patrol/day (the second column in Table 3).

During the 854 days there are no more than 2 accidents each day on the road, so the frequency of road accidents is 0,1 and 2 accident/day. $T_{i}$ is further divided into 3 groups based on the road accident frequency as $T_{i, 0}, T_{i, 1}$ and $T_{i, 2}$, then $T_{i, 0}+T_{i, 1}+T_{i, 3}=T_{i}$. For example, $T_{5}$ is divided into $T_{5,0}=155, T_{5,1}=$ 6 and $T_{5,2}=1, T_{5,0}$ represents the cumulated days while traffic police patrol frequency is 5 times/day and traffic accident rate is 0 accidents/day. $T_{5,1}=6$ represents the cumulated days with police patrol frequency being 5 patrol/day and traffic accident rate being 1 accident/day (The fourth column in Table 3). 


\begin{tabular}{|c|c|c|c|c|}
\hline $\begin{array}{c}\mathrm{i} \\
\text { (times /day) }\end{array}$ & $\begin{array}{c}\mathrm{T}_{\mathrm{i}} \\
\text { (days) }\end{array}$ & $\begin{array}{c}\mathrm{j} \\
\text { (crashes/day) }\end{array}$ & $\begin{array}{c}\mathrm{T}_{\mathrm{i}, \mathrm{j}} \\
\text { (days) }\end{array}$ & $\mathrm{T}_{\mathrm{ij}} / \mathrm{T}_{\mathrm{i}} \times 100 \%$ \\
\hline \multirow{4}{*}{5} & \multirow{3}{*}{162} & 0 & 155 & $95.7 \%$ \\
\hline & & 1 & 6 & $3.7 \%$ \\
\hline & & 2 & 1 & $0.6 \%$ \\
\hline & \multirow{3}{*}{150} & 0 & 137 & $91.3 \%$ \\
\hline \multirow[t]{2}{*}{6} & & 1 & 11 & $7.3 \%$ \\
\hline & & 2 & 2 & $1.3 \%$ \\
\hline & & 0 & 126 & $96.2 \%$ \\
\hline \multirow[t]{3}{*}{7} & \multirow[t]{2}{*}{131} & 1 & 5 & $3.8 \%$ \\
\hline & & 2 & 0 & $0.0 \%$ \\
\hline & \multirow{3}{*}{87} & 0 & 84 & $96.6 \%$ \\
\hline \multirow[t]{2}{*}{8} & & 1 & 1 & $1.1 \%$ \\
\hline & & 2 & 2 & $2.3 \%$ \\
\hline \multirow{3}{*}{9} & \multirow{3}{*}{56} & 0 & 52 & $92.9 \%$ \\
\hline & & 1 & 3 & $5.4 \%$ \\
\hline & & 2 & 1 & $1.8 \%$ \\
\hline \multirow{4}{*}{10} & & 0 & 42 & $95.5 \%$ \\
\hline & \multirow[t]{2}{*}{44} & 1 & 1 & $2.3 \%$ \\
\hline & & 2 & 1 & $2.3 \%$ \\
\hline & \multirow{3}{*}{32} & 0 & 32 & $100.0 \%$ \\
\hline \multirow[t]{2}{*}{11} & & 1 & 0 & $0.0 \%$ \\
\hline & & 2 & 0 & $0.0 \%$ \\
\hline \multirow{3}{*}{12} & \multirow{3}{*}{57} & 0 & 56 & $98.2 \%$ \\
\hline & & 1 & 1 & $1.8 \%$ \\
\hline & & 2 & 0 & $0.0 \%$ \\
\hline \multirow{3}{*}{13} & \multirow{3}{*}{66} & 0 & 64 & $97.0 \%$ \\
\hline & & 1 & 1 & $1.5 \%$ \\
\hline & & 2 & 1 & $1.5 \%$ \\
\hline \multirow{3}{*}{14} & \multirow{3}{*}{48} & 0 & 47 & $97.9 \%$ \\
\hline & & 1 & 1 & $2.1 \%$ \\
\hline & & 2 & 0 & $0.0 \%$ \\
\hline \multirow{3}{*}{15} & \multirow{3}{*}{21} & 0 & 21 & $100.0 \%$ \\
\hline & & 1 & 0 & $0 . \quad 0 \%$ \\
\hline & & 2 & 0 & $0.0 \%$ \\
\hline
\end{tabular}

When studying the number of accidents on a roadway segment over some period of time, the accident per vehicle or vehicle mile is more reasonable. During the investigation period, the number of vehicles possessed is time-dependent and the complete traffic flow on the road was not recorded, so it is impossible to study the fluctuation of accident per vehicle or vehicle mile. Alternatively, the ratio $P_{i, j}$ is defined as

$$
P_{i, j}=T_{i, j} / T_{i} \times 100 \%(\mathrm{i}=5,6, \cdots, 15 \text { and } \mathrm{j}=0,1,2)
$$

then, $P_{i, 0}+P_{i, 1}+P_{i, 2}=100 \%$.

While the subscript $j=0, P_{i, j}$ means ratio of the cumulated days while 0 accident/day and $i$ patrol/day to the accumulated days while $i$ patrol/day. If police patrol do has obvious effects on road safety, it can infer that $P_{i, 0}$ would increases while police patrol frequency $i$ increases; in the same way, $P_{i, 1}$ and $P_{i, 2}$ would decrease while police patrol frequency $i$ increases.

$P_{i, 0}=95.7 \%, 91.3 \%, 96.2 \%, \cdots, 100 \%$ is corresponding one to one with traffic police patrol frequency $i=5,6,7, \cdots, 15$ (see Table 3). The graphical relation between the frequency of police patrol $i$ and $P_{i, 0}$ is shown in Fig. 2 and regression analysis is conducted. For linear regression analysis the regression function is 


$$
P_{i, 0}=0.0055 i+0.9094 \text { with } R^{2}=0.4698 \text { and Significance } F=0.0199
$$

Figure 2: Police patrol frequency i against $P_{i, 0}$

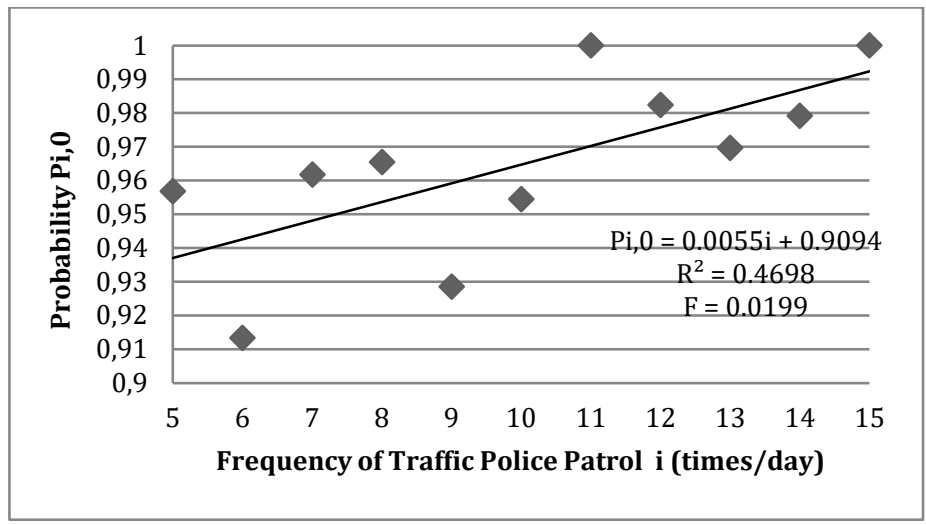

As the Significance $F$ is less than 0.05 the result is deemed reliable. It can see from the Fig. 2 that the $P_{i, 0}$ rises approximately in proportion to the increasing of the police patrol frequency $i$. The higher the police patrol frequency $i$ accompanies with the larger $P_{i, 0}$. There is a positive relationship between police patrol frequency $i$ and $P_{i, 0}$.

While $j=1, P_{i, 1}$ represents the ratio of cumulated days while road accidents frequency is 1 accident/day and the traffic police patrol frequency is $i$ patrol/day to the cumulated days while police patrol frequency is $i$ patrol/day. $P_{i, 1}=3.7 \%, 7.3 \%, 3.8 \%, \cdots, 0.0 \%$ corresponds one to one with patrol frequency $i=5,6,7, \cdots, 15$. The relationship between the frequency of police patrol $i$ and $P_{i, 1}$ is shown in Fig. 3 and regression analysis is also conducted. The regression function is

$$
P_{i, 1}=-0.0046 i+0.0723 \text { with } R^{2}=0.4596 \text { and Significance } F=0.0218
$$

Figure 3: Police patrol frequency i against $P_{i, 1}$

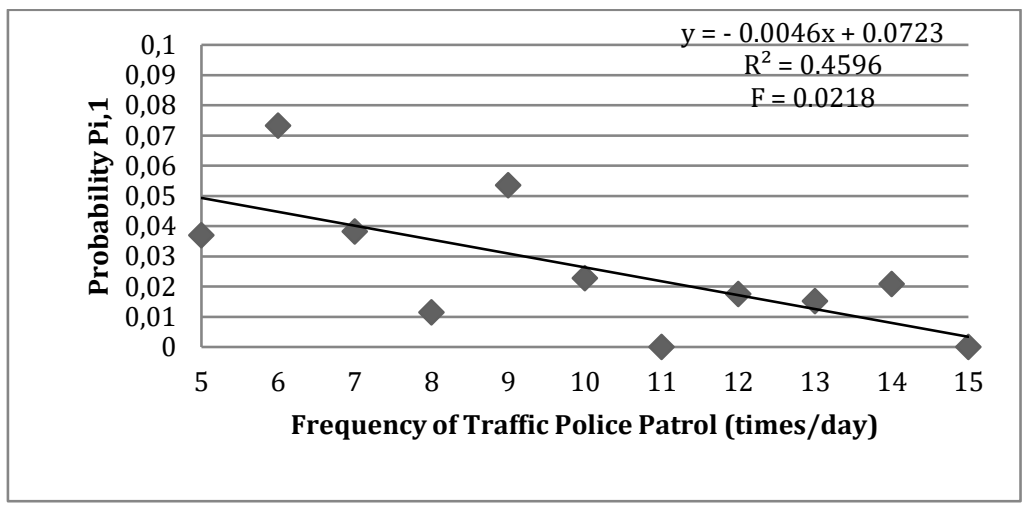

From the results, it is easy to see that larger police patrol frequency accompanied with the smaller $P_{i, 1} \cdot P_{i, 1}$ has a decreasing trend while traffic police patrol frequency increases. The results of two linear regression analyses verified our hypothesis. For $j=2$, data about $T_{i, 2}$ is not enough to conduct data analysis.

\section{Conclusions}

In this study, data set collected from a road segment of $58.4 \mathrm{~km}$ length is employed to investigate the effect of safety measures in China. The data applied includes the self-reported questionnaire survey, traffic police patrol frequency and road crash frequency. The results show that

1. Driving after drinking, speeding, fatigued driving and jaywalking are the primary reasons for the crashes on the road segment investigated, 
2. Traffic police patrol is the most effective safety measure on the road and all the drivers participated in the questionnaire survey admitted that police patrol do change their illegal driving behaviour and

3. Increasing the frequency of police patrol has a positive effect on improving the road safety by the statistical regression analysis, and it is consistent with the results from self-reported questionnaire survey.

The result is consistent with previous worked conducted by Lu et al. in Tsingdao China, who revealed that traffic tickets issued by police had a deterrence effect (Lu, Zhang \& Perloff, 2016).

There are a number of limitations to this investigation that should be mentioned. The investigation was carried out only on a road segment and result can't be a representative of the whole country. The variation of road condition was not considered in the analysis which actually has an impact on the road safety. For self-reported questionnaire survey, the amount of data is not large, larger random samples from the general public would be helpful. The number of data pool limit the further more detailed statistical analysis, the types of road crashes (fatal or nonfatal), the time distribution of the crashes (daytime or night-time) and the gender of drivers (male or female) was not analysed in study and this should be addressed in the future work while enough data has collected.

\section{Funding}

The authors received no direct funding for this research.

\section{Citation information}

Suo, Q., Suo, R., \& Zhang, D. (2018). Investigation and statistical analysis on the deterrence effect of police patrol. Journal of Sustainable Development of Transport and Logistics, 3(1), 69-76. doi:10.14254/jsdtl.2018.3-3.5

\section{References}

Briscoe, S. (2004). Raising the bar: Can increased statutory penalties deter drink -drivers?. Accident Analysis and Prevention, 36, 919-929.

Chang, L. Y., Lin, D. J., Huang, C. H., \& Chang, K. K. (2013). Analysis of contributory factors for driving under the influence of alcohol: A stated choice approach. Transportation Research Part F: Traffic Psychology and Behaviour, 18, 11-20.

Elvik, R. (2011). Developing an accident modification function for speed enforcement. Safety Science, 49, 920 -925.

European Commission. (2007). Part C, best practices in road safety: Handbook for measures at the country level. Retrieved from http://ec.europa.eu/transport/roadsafety_library/publications/supreme_c_handbook _for_measures_at_the_country_level.pdf

Grosvenor, D., Toomey, T. L., \& Wagenaar, A. C. (1999). Deterrence and the adolescent drinking driver. Journal of Safety Research, 30(3), 187-191.

Hakkert, A. S., Gitelman, V., Cohen, A., Doveh, E., \& Umansky, T. (2001). The evaluation of effects on driver behavior and accidents of concentrated general enforcement on interurban roads in Israel. Accident Analysis \& Prevention, 33(1), 43-63.

Kuo, P. F., Lord, D., \& Walden, T. D. (2013). Using geographical information systems to organize police patrol routes effectively by grouping hotspots of crash and crime data. Journal of Transport Geography, 30, 138-148.

Lapham, S. C., \& Todd, M. (2012). Do deterrence and social-control theories predict driving after drinking 15 years after a DWI conviction?. Accident Analysis \& Prevention, 45, 142-151.

Li, Y., Xie, D., Nie, G., \& Zhang, J. (2012). The drink driving situation in China. Traffic injury prevention, 13(2), 101108.

Liu, G., Ding, L., \& Wang, J. (2015). Thinking on strengthening the propaganda and education of traffic safety. Journal of People's Republic Security University of China (Science and Technology), 4, 50-54.

Lu, F., Zhang, J., \& Perloff, J. M. (2016). General and specific information in deterring traffic violations: evidence from a randomized experiment. Journal of Economic Behavior \& Organization, 123, 97-107.

National Bureau of Statistics of the PRC. (2013). China Statistical Yearbook of 2013. Retrieved from http://www.stats.gov.cn/tjsj/ndsj/2013/indexce.htm 
National People's Congress of PRC. (2004). Law of the People's Republic of China on Road Traffic Safety. Beijing, China Law Press.

National People's Congress of PRC. (2011). Law of the People's Republic of China on Road Traffic Safety. Beijing, China Law Press.

Newstead, S. V., Cameron, M. H., \& Leggett, L. M. W. (2001). The crash reduction effectiveness of a network-wide traffic police. Accident Analysis and Prevention, 33, 393-406.

Stanojević, P., Jovanović, D., \& Lajunen, T. (2013). Influence of traffic enforcement on the attitudes and behavior of drivers. Accident Analysis \& Prevention, 52, 29-38.

Suo, Q., Zhang, D., \& Liu, Y. (2017). Assessment of the Chinese driver licensing system implemented from 1 Jan 2013 to 30 Sep 2016. Transportation Research Part A: Policy and Practice, 100, 81-87.

Taxman, F. S., \& Piquero, A. (1998). On preventing drunk driving recidivism: An examination of rehabilitation and punishment approaches. Journal of Criminal Justice, 26(2), 129-143.

Vaa, T. (1997). Increased police enforcement: effects on speed. Accident Analysis \& Prevention, 29(3), 373-385.

Wright, V. (2010). Deterrence in Criminal Justice. Retrieved from http://www.sentencingproject.org/wpcontent/uploads/2016/01/Deterrence-in-Criminal-Justice.pdf

Yannis, G., Papadimitriou, E., \& Antoniou, C. (2007). Multilevel modelling for the regional effect of enforcement on road accidents. Accident Analysis \& Prevention, 39(4), 818-825.

Yannis, G., Papadimitriou, E., \& Antoniou, C. (2008). Impact of enforcement on traffic accidents and fatalities: A multivariate multilevel analysis. Safety Science, 46(5), 738-750.

Zhang, W., Tsimhoni, O., Sivak, M., \& Flannagan, M. J. (2010). Road safety in China: analysis of current challenges. Journal of safety research, 41(1), 25-30.

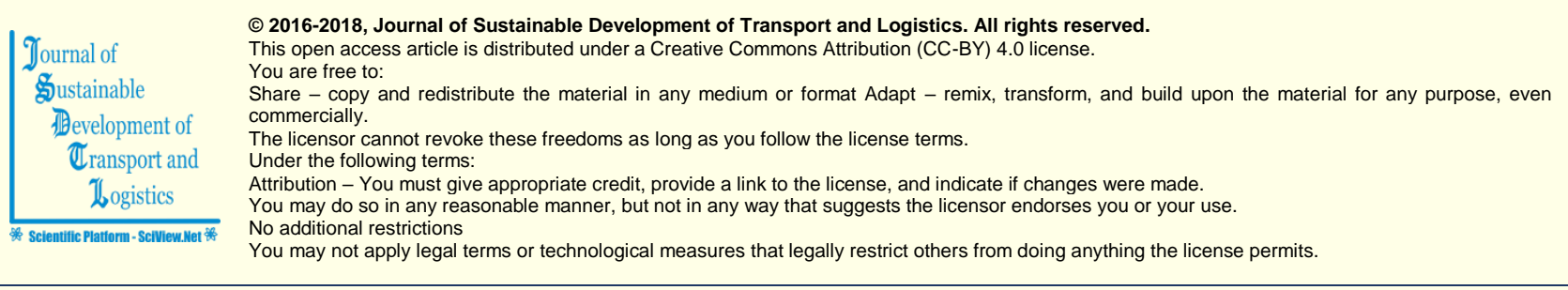

Journal of Sustainable Development of Transport and Logistics (ISSN: 2520-2979) is published by Scientific Publishing House "CSR", Poland, EU and Scientific Publishing House "SciView", Poland, EU

Publishing with JSDTL ensures:

- Immediate, universal access to your article on publication

- High visibility and discoverability via the JSDTL website

- Rapid publication

- Guaranteed legacy preservation of your article

- Discounts and waivers for authors in developing regions

Submit your manuscript to a JSDTL at https://jsdtl.sciview.net/ or submit.jsdt|@sciview.net 